\title{
РОЛЬ РОДИТЕЛЕЙ В ПОКАЗНОМ ПОТРЕБЛЕНИИ ДЕТЕЙ СТАРШЕГО ДОШКОЛЬНОГО ВОЗРАСТА
}

Молчанова Г.В. (Московский педагогический государственный университет, Москва, Россия) gvmolch@mail.ru

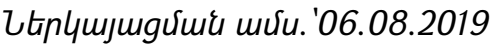

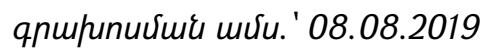

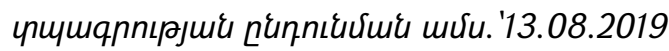

Показное потребление в детском возрасте имеет отличительные особенности: выполняет в большей мере компенсаторные функции. Дисгармоничный стиль воспитания в семье провоцирует трудности в общении у детей. Дети не имеют необходимых средств для адекватной коммуникации со сверстниками, поэтому они используют показное потребление как доступное $и$ понятное им средство поддержания коммуникации. Стиль воспитания в семье и доминирующий мотив показного потребления в дошкольном возрасте имеет тесную взаимосвязь.

Ключевые слова: показное потребление, дошкольник, дети дошкольного возраста, дисгармоничный стиль воспитания.

Общение - необходимое условие психического развития ребенка. Первая коммуникация формируется в рамках семейной системы, благодаря которой удовлетворяются основные потребности ребенка. Доброжелательное и открытое отношение значимого взрослого является критерием формирования социальнопозитивных особенностей ребенка. Выражение раздражительности и экспроприации, неприкрытой небрежности со стороны значимых взрослых, навязывают ребенку желание воздержаться от неприятных эмоций, приводят к запиранию в себе. Экспроприация со стороны членов семьи может способствовать изоляции ребенка в коллективе [3, с.42]. Отношение взрослых к ребенку содержит в своей основе избирательное его понимание, специфичный образ, метод общения и тип воздействия на него. Наиболее значимые различия наблюдаются между гармоничным и дисгармоничным стилем воспитания.

Определяя дисгармоничный стиль воспитания, Эйдемиллер Э. Г. говорит о «...стабильном комбинировании разных выраженных характерностей воспитания, конкретнее: степень протекции, уровень требований к ребенку (требования обязанности, строгость санкций, степень запретов), достаточность удовлетворения потребностей ребенка, степень зыбкости стиля воспитания» [4, с.16]. В последнее время в России наблюдается рост процента дисгармоничных семей, в которых нарушен процесс взаимодействия между ее членами. По результатам нашего исследования, проведенного в 2018-2019 гг., число детей, воспитывающихся в дисгармоничных семьях, значительно превышает число детей, воспитывающихся в 
семьях с гармоничным стилем воспитания (63\% и $37 \%$ соответственно). Доминируют четыре дисгармоничных стиля семейного воспитания: повышенная моральная ответственность $(25,8 \%)$, доминирующая гиперпротекция $(25,8 \%)$, скрытая гипопротекция (25,8\%), потворствующая гиперпротекция (22,6\%). При этом в семьях с гармоничным стилем воспитания в 77\% случаев в родительскодетских отношениях наблюдается оптимальный эмоциональный контакт. В то время как в дисгармоничных семьях, при потворствующей гиперпотекции, в родительскодетских отношениях наблюдается самопожертвование матери $(31,8 \%$.), сверхснисходительность в отношении к ребенку, мать значительное количество времени проводит с ребенком, обвиняя себя в его неудачах. При стиле воспитания доминирующая гиперпротекция - в родительско-детских отношениях наблюдается доминирование матери - 27,2\%, проявляя чрезмерную зависимость от ребенка мать усиливает подчиненность ребенка. При повышенной моральной ответственности чрезмерная концентрация на ребенке - 27,2\%. Матери свои достижения видят в том, что полностью сосредоточены на ребенке, желая ускорить его развитие и воспитать гармоничную личность. При скрытой гипопротекции - наблюдается излишняя эмоциональная дистанция с ребенком - 31,8\%. На ребенка перекладываются все материнские ожидания и опасения, таким образом, нарушая ход его развития. Ребенок испытывает отрицательные чувства по отношению к матери, закрывается от нее, становясь более самостоятельным в одиночестве [1].

Ребенок, воспитывающийся в дисгармоничной семье, в итоге не получает адекватных навыков коммуникации, что провоцирует трудности взаимодействия со сверстниками уже в дошкольном возрасте. Дошкольники начинают использовать показное потребление как механизм компенсации трудностей в общении. Под показным потреблением понимается удовлетворение нематериальных потребностей материальными способами.

Приобретенные товары неоднократно используются ребенком для формирования хорошего впечатления о себе, получения высокой социальной оценки у авторитетных сверстников, создания своего неповторимого стиля. При взаимодействии друг с другом, игрушка у детей является средством для достижения некоторых целей общения. Например, кто-то желает быть похожим на друзей, принося подобные игрушки для осуществления своих целей. Другой хочет быть замеченным, увидев у него игрушку не такую как у всех. Некоторые дети просто хотят наладить общение и иметь много друзей. Есть дети, которые с помощью игрушки стараются заинтересовать понравившегося ровесника и т.д. [2]. Сегодня дошкольники сконцентрированы на серии игрушек. Они старательно собирают наборы таких игрушек, постоянно дополняя их. Имея коллекционную игрушку ребенок может быть принят другими детьми в группе, которые тоже собирают такие игрушки. Это своего рода способ поднятия статуса, путем состязания, кто больше соберет игрушек из набора. 
Сегодня актуально определить мотивы показного потребления у детей дошкольного возраста, воспитывающихся в семьях с дисгармоничным и гармоничным стилях воспитания, чтобы формировать специализированные программы развития коммуникативных навыков. В 2018-2019 гг. под нашим руководством Цой Е.А. проведено обширное исследование с целью определить специфику мотивом показного потребления у детей, воспитывающихся в гармоничных и дисгармоничных семьях. Гипотеза исследования: стиль семейного воспитания определяет доминирующий мотив показного потребления детей старшего дошкольного возраста. Методики исследования: методика "Анализ семейных взаимоотношений" (ACB) (Эйдемиллер Э.Г. Юстицкис); методика «PARI» (Е. С. Шевер, Р. К. Белл, адаптирована Т. В. Нещерет); проективная методика «Мотивы показного потребления в детском коллективе» (Г. В. Молчанова, В. И. Чупрынина); методика «Особенности межличностных отношений (ОМО) для детей» (У. Шутц, модификация и критерии анализа Г.Р. Хузеевой).

В исследовании приняли участие 92 ребенка в возрасте 5;6 - 6;2, посещающих ДОУ «Детский сад № 2» г. Звенигорода; а также 80 матерей и 10 отцов.

Результаты исследования показали, что у дошкольников из семей с гармоничным стилем воспитания доминируют два ключевых мотива показного потребления: наладить взаимоотношения (38,2\%) и завести новые знакомства $(29,4 \%)$. Открытость коммуникации в семьях с гармоничным стилем воспитания, удовлетворение потребностей каждого члена семьи, включая детей, дает возможность дошкольникам из данных семей применять предметы показного потребления для дальнейшего развития коммуникативных умений в детском коллективе. В тоже время повышенная занятость родителей не позволяет сформировать устойчивые коммуникативные стереотипы, например, для начала или завершения общения. Такие дошкольники используют показное потребление для снижения тревожности при осуществлении проблемных для них моментов коммуникации.

В таблице 1 представлено соотношение стиля дисгармоничного семейного воспитания и мотивов показного потребления дошкольника, формы демонстрации показного потребления и специфики родительско-детских отношений. Активная форма показного потребления - когда ребенок активно использует предметы показного потребления в решении коммуникативных проблем, пассивная фрорма показного потребления - когда ребенок проецирует собственные мотивы показного потребления другим участникам коммуникации, в качестве объяснительного механизма. Смешанная форма - когда ребенок считает возможным самому использовать предметы показного потребления для решения коммуникативных трудностей, но активно еще не пробовал. 
Таблица 1.

Дисгармоничный стиль воспитания и доминанты мотивов показного потребления и родительско-детских отношений

\begin{tabular}{|l|c|c|c|}
\hline \multicolumn{1}{|c|}{\begin{tabular}{c}
\multicolumn{1}{c|}{ стмлияьн } \\
воспитания
\end{tabular}} & $\begin{array}{c}\text { Доминирующий } \\
\text { мотив показного } \\
\text { потребления }\end{array}$ & $\begin{array}{c}\text { Форма } \\
\text { демонстрации } \\
\text { показного } \\
\text { потребления }\end{array}$ & $\begin{array}{c}\text { Родительско- } \\
\text { детские отношения }\end{array}$ \\
\hline $\begin{array}{l}\text { Потворствующая } \\
\text { гиперпротекция }\end{array}$ & $\begin{array}{c}\text { Желание } \\
\text { выделиться }\end{array}$ & Активная & $\begin{array}{c}\text { Самопожертвование } \\
\text { в роли матери }\end{array}$ \\
\hline $\begin{array}{l}\text { Доминирующая } \\
\text { гиперпротекция }\end{array}$ & $\begin{array}{c}\text { Желание привлечь } \\
\text { внимание }\end{array}$ & Пассивная & $\begin{array}{c}\text { Доминирование } \\
\text { матери }\end{array}$ \\
\hline $\begin{array}{l}\text { Повышенная } \\
\text { моральная } \\
\text { ответственность }\end{array}$ & $\begin{array}{c}\text { Желание } \\
\text { выделиться }\end{array}$ & Смешанная & $\begin{array}{c}\text { Излишняя } \\
\text { концентрация на } \\
\text { ребенке }\end{array}$ \\
\hline $\begin{array}{l}\text { Скрытая } \\
\text { гипопротекция }\end{array}$ & $\begin{array}{c}\text { Желание привлечь } \\
\text { внимание }\end{array}$ & Активная & $\begin{array}{c}\text { Эмоциональная } \\
\text { дистанция }\end{array}$ \\
\hline
\end{tabular}

У детей, воспитывающихся в семьях с потворствующей гиперпротекцией, доминирующий мотив показного потребления - желание выделиться (62\%). Характерными чертами воспитания по типу «ребенок - кумир семьи» являются чрезмерное покровительство, стремление освободить ребенка от малейших трудностей, удовлетворить все его потребности. Все это приводит к развитию эгоцентрических тенденций в личности ребенка. Такой ребенок, принося модную игрушку в дошкольное учреждение - тем самым выделяет себя. Тогда желанную коммуникацию со сверстниками не надо специально выстраивать и поддерживать, она происходит сама по себе, по поводу игрушки. Тем самым дошкольник решает коммуникативную проблему привычным для него способом, способом, который культивируется в его дисгармоничной семье.

У детей, воспитывающихся в семьях с доминирующей гиперпротекцией, доминирующим мотивом показного потребления является желание быть похожим на сверстника (53\%). Чрезмерный контроль, интенсивность воспитательных мероприятий в стиле воспитания приводит к невозможности для ребенка принять когда-либо собственные решения, что порождает зависимость, несамостоятельность, инфантилизм, неуверенность в себе, избегание риска. В данном случае, модная игрушка тоже позволяет решать проблемы коммуникации привычным для их семьи способом.

У детей, воспитывающихся в семьях с повышенной моральной ответственностью, доминирующим мотивом показного потребления также является желание быть похожим на сверстника (60\%). При этом стиле воспитания к ребенку предъявляются повышенные требования с пониженным вниманием к его 
потребностям. Ребёнок эмоционально уплощен, не умеет вписываться в меняющиеся условия. Такому дошкольнику легче слиться с большинством сверстников, «быть как все», что приводит к автоматическому принятию его как члена группы.

у детей, воспитывающихся в семьях со скрытой гипопротекцией, доминирующий мотив показного потребления - привлечь внимание (53\%). При данном стиле воспитания дошкольники понимают, что родители не будут уделять им внимание, удовлетворять их потребности, поэтому дети, не имея необходимых навыков в общении, вынуждены привлекать внимание сверстников модными игрушками.

Таким образом, дисгармоничный стиль воспитания в семье провоцирует коммуникативные трудности у дошкольника. Ребёнок начинает использовать предметы показного потребления в качестве компенсации своих трудностей, обусловленных недостаточностью заботы, внимания, опеки и контроля со стороны родителей, интереса к ребенку и удовлетворения его потребностей. Дисгармоничное воспитание в семье мешает налаживанию адекватного взаимодействия ребенка в семье, затрудняет его социальную адаптацию. Существует значимая взаимосвязь между стилем воспитания и доминирующим мотивом показного потребления ( $r$ (Пирсона) $=0,54$, при $p<0,01)$.

\section{Выводы:}

Показное потребление в детском возрасте имеет отличительные особенности: выполняет в большей мере компенсаторные функции.

Дисгармоничный стиль воспитания в семье провоцирует трудности в общении у детей. Дети не имеют необходимых средств для адекватной коммуникации со сверстниками, поэтому они используют показное потребление как доступное и понятное им средство поддержания коммуникации.

У дошкольников из семей с гармоничным стилем воспитания доминируют два мотива показного потребления: «наладить взаимоотношения" $(38,2 \%)$ и «завести новые знакомства» $(29,4 \%)$.

Доминирующими мотивами показного потребления у дошкольников из семей с дисгармоничным стилем воспитания являются: «желание выделиться» и «желание привлечь внимание».

\section{Литература}

1. Молчанова Г.В. Диагностический практикум : показное потребление в детском возрасте: учебное пособие / Г. В. Молчанова. - Москва : МПГУ, 2018. - 80 c.

2. Психология дошкольного возраста. Часть 2 / Е. И. Изотова [и др.]; под ред. Е. И. Изотовой. -М.: Издательство Юрайт, 2018. - 222 с.

3. Титаренко В. Я. Семья и формирование личности. - М., 1987. 
4. Eydemiller E., Yustitskis V. Psihologiya I psihoterahiya sem'i [Psikhologiya and psychotherapy of family], SPb.: Piter Publ. (In Russian) (2006).

\section{THE ROLE OF PARENTS IN CONSPICUOUS CONSUMPTION OF PRESCHOOL CHILDREN}

Molchanova G.V. (MPSU, Moscow, Rassia)

Conspicuous consumption in childhood has distinctive features. It performs compensatory functions. Disharmonious parenting style of education provokes difficulties in communication in children. Children have not the necessary communicative skills to communicate adequately with their peers. They use conspicuous consumption as base of interaction.

Keywords: conspicuous consumption, preschool children, disharmonious parenting style of education. 